\title{
Drug Seller Provision Practices and Knowledge of Misoprostol in Bangladesh
}

\begin{abstract}
CONTEXT: In Bangladesh, prior to the availability of the approved combination regimen of mifepristone and misoprostol for menstrual regulation (MR), drug seller provision of misoprostol-only regimens for MR without a prescription was widespread but service quality was poor. Examining provider practices relating to misoprostolonly provision in Bangladesh may increase understanding of misoprostol use and provision in other low-resource, legally restrictive settings.
\end{abstract}

METHODS: In 2013-2014, a countrywide cross-sectional knowledge, attitudes and practice survey was conducted among 777 randomly selected drug sellers; data were analyzed descriptively. Logistic regression was used to test the associations between exposure to three interventions designed to improve drug seller practice (nongovernmental organization [NGO]-led training, a call center and in-shop training from pharmaceutical company representatives) and correct knowledge of the misoprostol-only MR regimen.

RESULTS: Almost all (97\%) of the drug sellers reported providing medications intended for MR; misoprostol-only was more commonly sold than the combination regimen ( $96 \%$ vs. 26\%). Nine percent had received NGO-led training, $62 \%$ had received in-shop training from a pharmaceutical company representative and $27 \%$ had used the call center. Overall, $19 \%$ of drug sellers knew the correct misoprostol-only MR regimen, and $74 \%$ wanted more information about this regimen. Correct regimen knowledge was positively associated with receipt of NGO training and call center utilization (odds ratios, 2.0 and 1.9, respectively).

CONCLUSIONS: NGO-led training and call centers should be considered in other settings in which misoprostol alone is provided off-label for pregnancy termination.

International Perspectives on Sexual and Reproductive Health, 2019, 45:45-54, https://doi.org/10.1363/45e7819

In Bangladesh, induced abortion is allowed only to save a woman's life; however, in 1979, the government officially approved menstrual regulation (MR) as one of the methods of the family planning program to reduce morbidity and mortality related to unsafe abortion. ${ }^{1} \mathrm{MR}$, a procedure to regulate the menstrual cycle after a missed menstrual period, is available free of charge to women at risk of pregnancy for up to 12 weeks since last menstrual period; the procedure is typically performed using manual vacuum aspiration at government hospitals, and health and family welfare clinics. ${ }^{1}$ Because pregnancy is not confirmed prior to the procedure, MR is not regulated by the penal code restricting abortion. ${ }^{2}$ Despite MR's availability, in 2014, an estimated 1,194,000 pregnancy terminations in Bangladesh took place outside of the formal health care sector-nearly three times the number of clinic-based MRs-and an estimated 384,000 women experienced complications from their abortion procedure. ${ }^{3}$

In February 2013, the first combination medication abortion regimen of mifepristone and misoprostol was accepted by the National Drug Administration of Bangladesh and came onto the market as an alternative to surgical MR; a second brand was approved and became available later that year. In 2015, medication MR was incorporated into the national family planning program to be administered by trained doctors or mid-level providers up to nine weeks since last menstrual period. ${ }^{4}$ Although the combination regimen has therefore been available by prescription from private and nongovernmental organization (NGO) clinics and drug sellers* since $2013,{ }^{5}$ penetration of the product into the public health system has been somewhat slow. ${ }^{6}$

However, the drug misoprostol on its own has been increasingly used since the late 1980s as a safe alternative to surgical methods for terminating a first-trimester pregnancy and is now recommended in the World Health Organization's abortion guidelines for this indication where mifepristone is not available. ${ }^{7,8}$ The practice of selfadministration of drug shop-procured misoprostol alone as an abortifacient has been documented in settings other than Bangladesh and has been termed a "harm reduction approach," providing women with a safer alternative to clandestine methods of abortion when legal services are not available. ${ }^{9}$ In Latin America, this practice has contributed to declines in rates of severe abortion-related

*In this article, we use the terms drug seller and drug shop to refer to any individual and outlet selling medications, whether or not they are trained or registered to do so.
By Kate Reiss, Katherine Keenan, Kathryn Church, Sally Dijkerman, Shahida Akter Mitu, Sadid Nuremowla and Thoai D. Ngo

Kate Reiss is research degree student, Faculty of Epidemiology and Population Health, London School of Hygiene and Tropical Medicine, London. Katherine Keenan is lecturer in demography, Department of Geography and Sustainable Development, University of St. Andrews, Scotland. Kathryn Church is director of global evidence, Technical Services Department, Marie Stopes International, London. Sally Dijkerman is senior research and evaluation officer Ipas, Chapel Hill, NC, USA. Shahida Akter Mitu is monitoring and evaluation officer, Directorate General of Health Services, Dhaka, Bangladesh. Sadid Nuremowla is an independent consultant, Dhaka, Bangladesh. Thoai D. Ngo is director, Poverty, Gender and Youth Program, Population Council, New York. 
complications and deaths. ${ }^{10,11}$ Misoprostol on its own is not an approved MR treatment in Bangladesh, but the drug is registered for gastric ulcer and postpartum bleeding, and thus can be legally sold by registered drug sellers for these indications with a prescription. In 2011, a mystery client survey conducted among 331 registered and unregistered drug shops from two districts of Bangladesh showed that misoprostol-only was commonly available over the counter for MR. ${ }^{5}$

In many low-resource settings, including Bangladesh, drug sellers or pharmacy workers play a key role in reproductive health care, ${ }^{12-14}$ and are often preferred by clients because of their convenience, discretion and accessibility. ${ }^{15,16}$ In Bangladesh, the Directorate General of Drug Administration, the body responsible for issuing licenses to sell medicines, reported that there were 97,357 registered pharmacies in the country in 2014. ${ }^{17}$ To qualify for registration, a pharmacy or medicine shop must have an employee who has a minimum of a secondary school certificate in science, has completed an 80-hour dispensing training with the Pharmacy Council of Bangladesh and has passed the related exam. ${ }^{18}$ In addition to the registered providers, there were an estimated 30,000-100,000 unregistered drug sellers in 2014. 5,17,18

Because misoprostol alone is not registered for use for MR in Bangladesh, no instructions are printed on its packet for this purpose and clients are reliant on drug sellers' advice for appropriate dosage. However, drug seller provision of the misoprostol-only regimen for MR without a prescription (or for medication abortion in other settings) is associated with poor quality provider knowledge and patient counseling. ${ }^{19}$ The mystery client survey conducted in Bangladesh in 2011 found that only 7\% of drug sellers advised an effective misoprostol-only MR dosage. ${ }^{5}$ Recommending an ineffective misoprostol dose may result in failed or incomplete MR procedures. ${ }^{20,21}$

Using a postintervention, national, cross-sectional survey conducted in 2013-2014, this study aims to document drug seller knowledge and self-reported provision of misoprostol-only and mifepristone plus misoprostol medications across the country shortly after the combination pack was introduced. The heterogeneous provider landscape of licensed and unlicensed drug sellers, selfmedication and widespread availability of the misoprostolonly method of medication abortion as an alternative to legal abortion is not unique to Bangladesh; many countries of Africa have similar features. Hence, an examination of provider knowledge and practices relating to misoprostolonly provision in Bangladesh provides important baseline data for the country, but may be valuable to elucidate misoprostol use and provision in other low-resource, legally restrictive settings.

We also report on three nationwide program strategies introduced in Bangladesh prior to 2013 that aimed to improve drug seller knowledge and end-user care for women seeking misoprostol-only MR treatments, and investigate whether exposure to such strategies is associated with drug seller knowledge. Although misoprostol alone is not an approved method for MR within the Bangladesh family planning program, it is commonly used for this purpose, and the practice is widely referred to as MR at the community level. ${ }^{22}$ This term was therefore used in the intervention and survey tools; the language is also consistent with other research on this topic., ${ }^{5,23}$

\section{Exposure Interventions}

Research from low- and middle-income countries has shown that introducing training programs for drug sellers can improve their reproductive health care knowledge and practice, including in relation to medication abortion provision. ${ }^{19}$ Between 2008 and 2010, Marie Stopes Bangladesh ran in-shop training sessions with drug sellers from approximately 4,000 shops surrounding all of the Marie Stopes clinics located in 62 out of 64 Bangladeshi districts. Outreach trainers (university graduates, most with medical or pharmacy qualifications) visited drug shops selling misoprostol at least once per month to give drug sellers verbal information on the most effective misoprostol-only regimen for MR.t They also provided information on side effects, complications and referral options.

The second initiative was the establishment of a call center in 2010 by Marie Stopes Bangladesh to improve knowledge of the correct use of medications for MR among users and those providing it. The call center, which was still operating at the time of this study, was open 24 hours, seven days per week, and was manned in shifts by physicians at Marie Stopes Bangladesh until 2011, when three paramedics were hired and trained as dedicated call center operators. The number was not toll free, but call center operators would return missed calls. From 2012, the call center phone number was printed on the packet and foil of one misoprostol product, and the service and phone number were advertised in drug shops on posters, flyers, wallet-sized cards, stickers and hanging cards. From September 2011, call center operators were trained to record who the caller was (e.g., provider, MR user, husband), and from July 2012, they recorded the reason for the call and other basic information.

The third initiative, "pharmaceutical company detailing," consisted of in-pharmacy training delivered by representatives of a national pharmaceutical company when they visited drug shops to distribute branded misoprostol and other drugs; this activity began in 2011 and was ongoing at the time of the study. The representatives were trained to give verbal information to drug sellers to whom they sold misoprostol, including on correct use of the product for MR (e.g., eligibility, most effective regimen, side effects and complications).

We are not aware of any other interventions to improve drug sellers' knowledge of using misoprostol for MR

TThe most effective misoprostol-only regimen for MR is defined as three doses of $800 \mu \mathrm{g}$ misoprostol, with three hours between each dose, taken vaginally, buccally or sublingually up to nine weeks since last menstrual period. 
taking place at the time of the interventions included in this study.

\section{METHODS}

\section{Study Setting and Design}

Between November 2013 and February 2014, we conducted a cross-sectional knowledge, attitudes and practice survey among drug sellers from all seven geographical divisions of Bangladesh; $\neq$ the study was approved by the Marie Stopes International Ethical Review Committee and the Bangladesh Medical Research Council. Because of the large number of unregistered drug sellers in Bangladesh, no complete sampling frame of drug shops exists. In October 2013, we obtained a list of 10,285 drug shops from the pharmaceutical company conducting the in-shop training visits. The list included the names and locations of all outlets in 57 of the 64 districts of Bangladesh that had been supplied misoprostol by the pharmaceutical company in the previous three months. We used systematic sampling to select 120 drug shops from each division. In each division, the total number of drug shops in the sampling frame was divided by 120 to obtain a sampling interval. The drug shops were numbered in the order in which they were received from the pharmaceutical company. The first drug shop was selected using Excel to generate a random number, and the sampling interval was repeatedly added to the first number to obtain the remaining 119 outlets.

Field workers from Marie Stopes Bangladesh visited each drug shop and recruited one worker to take part in the survey. Drug sellers were eligible to participate if they had worked at the shop for six months and were involved in selling drugs; if more than one drug seller met the inclusion criteria, the owner or longest serving worker was selected. All participants gave verbal consent to participate, and confidentiality was ensured by using anonymous identification codes for each individual and shop. Because providing medications for MR without a prescription is not approved in Bangladesh and drug sellers could face negative consequences if provision without a prescription was disclosed, extra care was taken to maintain anonymity.

Our planned sample of 120 drug shops per division allowed us to detect the population proportion of drug shops listed in our sampling frame in each division where the respondent knew the correct misoprostol-only regimen with a precision of plus or minus $10 \%$ and a significance of .05 , under the assumption that $50 \%$ did so. Eight hundred and forty drug shops were selected, 120 from each division, which allowed for a $17 \%$ refusal rate. We were able to locate 796 of the sampled drug shops; however, 15 of these had no drug seller willing to participate, and two had no eligible drug seller. In total, 779 drug sellers were interviewed; two of these interviews were terminated midway through and were not included in the analysis.

¥At the time of the study, there were seven divisions in Bangladesh.
The questionnaire was developed in English, translated into Bengali and then back translated into English. Prior to the study, the questionnaire was piloted with 15 drug sellers in 10 urban and semi-urban pharmacies in Dhaka division; after piloting, minor edits were made to the questionnaire to improve clarity and translation quality.

\section{Data Collection}

A field worker interviewed each participant and recorded their responses on a paper questionnaire that covered the characteristics of the provider and the drug shop, including age, gender, education and type of professional training; § years of experience selling misoprostol for MR; whether they were the owner of the drug shop; and the number of employees. Provision practices were assessed by asking respondents about the types of MR medications they provide and the cost, the types of advice and postcare they offer MR clients, the questions they ask prospective MR clients, perceived contraindications for provision of MR medications and whether they sell misoprostol for MR without a prescription.

The primary outcome was correct knowledge of the misoprostol-only regimen for MR advised in the exposure program interventions. The drug sellers had to demonstrate correct knowledge of four elements: the dose in micrograms (tablet size and number of tablets per dose), number of doses, hours between each dose and at least one route of administration. We also asked about the maximum time since the last menstrual period that MR should be taken, and knowledge of side effects and complications. In addition, participants were asked whether they had received pharmaceutical company detailing, if they had used the call center, if they had participated in NGO-led training or if they had had any other kind of training on misoprostol for MR; we created a series of corresponding dummy indicators for each type of training.

\section{Statistical Analysis}

To document drug seller knowledge and provision practices, we analyzed the data descriptively using tabulations showing sample distributions and proportions. Some variables had missing responses, which are shown or described in the tables.

The bivariate analysis and regression models were restricted to the 746 respondents who reported selling misoprostol in the last three months, and only included the 678 observations with complete data on the outcomes and explanatory variables. We conducted a bivariate analysis using chi-square tests to assess the associations between explanatory variables and the outcome, considering the following variables: drug shop characteristics (number of

\footnotetext{
§ln addition to the 1-2-year government diploma, professional pharmacy training for drug sellers could include one or more governmentapproved training (six-month pharmacist certificate training, 3-6-month local medical assistant and family planning training or three-month rural medical practitioner training) or training that has not been approved by the government, such as that provided by a pharmaceutical or social marketing company.
} 
drug sellers working at the outlet, division, number of MR clients per month), drug seller characteristics (age, education, professional training, years of experience, whether respondent sells misoprostol for other conditions), other training (having ever received training or information on using misoprostol for MR outside of the three study interventions) and program exposure (training, pharmaceutical company detailing and using the call center). We used multivariable logistic regression to test associations between program exposure and correct knowledge of MR regimen, adjusting for all of the variables listed above, except respondent's gender, because the small number of females created cell count issues. Data were analyzed using STATA 13.0.

\section{RESULTS}

Forty-two percent of drug shops had only one employee (Table 1). The majority of respondents were male (99\%), were aged 30 or older (75\%) and were drug shop owners (88\%); $60 \%$ had achieved their higher secondary certificate, and $88 \%$ had received some professional pharmacy training. Only 7\%, however, had received one or more years of professional training, indicating completion of a government-approved pharmacy diploma or degree. Eighty percent had received training lasting less than a year, and $11 \%$ had no training. Sixty-two percent had more than 10 years' experience selling drugs.

\section{MR Provision Practices}

Nearly all respondents (97\%) reported that they sold medications for MR (Table 2). Ninety-six percent reported providing misoprostol-only, and $26 \%$ the combination regimen. A further 29\% reported that they offered hormonal medications (oral contraceptives, emergency contraception or medication for secondary amenorrhea) to MR clients; these are not effective for MR, but it is possible that some hormonal medications could cause harm if taken during pregnancy. Four percent reported providing other medication not effective for MR (such as herbal medicine or iron pills). When asked how they respond to a customer asking about MR services, $82 \%$ reported offering MR medications for purchase, $30 \%$ advised clients to continue with their pregnancy and $82 \%$ referred clients to health facilities, to medical providers or for counseling. Ninety-seven percent reported stocking and selling misoprostol in the previous three months.

Among the participants who had stocked and sold misoprostol in the last three months, quality of care varied: Some 94\% reported asking for the date of the last menstrual period, $44 \%$ asked questions about medical history or medication allergies, 36\% asked about use of MR or emergency contraception since last menstrual period and 13\% asked whether the end user had an IUD inserted. Thirty-nine percent of participants reported that they asked for personal details before offering MR medications (e.g., third-party permission or reasons for MR). The most common reasons stated for why a woman should not be given medications for MR were allergies or

TABLE 1. Percentage distribution of drug shops and drug sellers participating in a knowledge, attitudes and practice study on misoprostol for menstrual regulation, by selected characteristics, Bangladesh, 2013-2014

Characteristic $(\mathrm{N}=777)$

\section{DRUG SHOP}

Division

Dhaka

Khulna

Chittagong

Rangpur

Rajshahi

Sylhet

Barisal

No. of workers

1

$\geq 3$

Missing

31.8

24.7

DRUG SELLER

Gender

Male

Female

Age

$<30$

30-39

$\geq 40$

\section{Education}

$\leq$ secondary

Higher secondary certificate

$\geq$ bachelor's

Professional pharmacy training

None

$<1$ yeart

1-2-year government-approved diploma

Missing

\section{No. of years in profession}

$<10$

$\geq 10$

Owner of drug shop

Yes

88.4

No

Total

tIncludes one or more government-approved training (six-month pharmacist certificate training, 3-6-month local medical assistant and family planning training or three-month rural medical practitioner training) or training that has not been approved by the government, such as that provided by a pharmaceutical or social marketing company. Note: Percentages may not total 100.0 because of rounding.

medical contraindications (62\%) and length of time since last menstrual period (more than nine weeks, $40 \%$; more than seven weeks, 25\%). In terms of client follow-up, 92\% reported providing MR clients with a phone number to call for more information, and 54\% reported referring clients to a health facility if they returned with heavy bleeding, incomplete MR or signs of infection. Eighty-eight percent reported offering family planning services post-MR. Among those who sold misoprostol-only for MR, 92\% reported doing so without a prescription. The median number of misoprostol clients in the previous month was seven. 
Fifty-seven percent of drug sellers had heard of the combination regimen, but only $37 \%$ of drug shops sold it (not shown). Among 290 drug shops offering the combination regimen, the median estimated number sold per month was five. The reported mean cost of the combination regimen kits ranged from 212 Bangladesh taka (BDT; US\$2.72) to BDT 270 (US\$3.45). By comparison, each

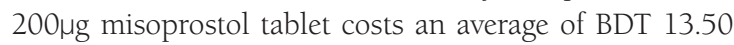
(US\$0.17) for the cheapest brand and BDT 15 (US\$0.19) for the most expensive. For the full, most effective regimen of 12 tablets, the cost of misoprostol-only MR treatment would range from BDT 162 (US\$2.07) to BDT 180 (US\$2.31), cheaper than the mifepristone-misoprostol approved MR regimen.

\section{Training and Knowledge}

Among drug sellers who reported stocking and selling misoprostol in the previous three months, $72 \%$ had received one or more types of training or orientation on using misoprostol-only for MR (Table 3). Just 9\% had received NGO training, 62\% pharmaceutical company detailing and $27 \%$ had used the call center. Only 16\% of respondents felt they had sufficient knowledge about using misoprostol-only for MR; $74 \%$ said they would like to know more about the regimen, $78 \%$ about side effects and complications, and $32 \%$ about when to prescribe MR medications.

Nineteen percent of respondents had correct knowledge of the recommended misoprostol-only MR regimen. Fifty-two percent knew the correct dosage per dose, 34\% knew that there should be three doses, 58\% knew that there should be three hours between doses and $85 \%$ knew at least one correct administration route. Thirty percent identified a total dose that was lower than the optimal regimen, and 29\% identified a higher dose. In terms of eligibility, only $11 \%$ of respondents correctly stated the maximum time since the last menstrual period recommended in Bangladesh for MR with medication (nine weeks); 48\% stated a lower limit, 36\% stated 10-12 weeks and $2 \%$ stated more than 12 weeks. Forty-one percent of respondents identified five potential side effects, and 53\% identified two serious complications.

\section{Multivariable Findings}

In models adjusted for division, drug shop and drug seller characteristics, those who had received NGO-led training or used the call center had increased odds of knowledge of correct regimen (odds ratios, 2.0 and 1.9, respectivelyTable 4). The odds of correct knowledge were lower in Khulna, Chittagong, Rangpur and Barisal than in Dhaka (0.2-0.5), and higher among those who had sold misoprostol for MR for two or more years than among those with less experience (1.7). We explored whether receiving more than one intervention or receiving particular combinations of interventions improved knowledge using interaction terms in the logistic regression models, but found no evidence to support these types of effects.
TABLE 2. Menstrual regulation provision practices among drug sellers in Bangladesh

Practice $\% /$ mean

ALL RESPONDENTS ( $\mathrm{N}=777)$

Provides medications for MRt

Any MR medication

Mifepristone-misoprostol combination

Misoprostol-only

conal medications not effective for MR (oral contraceptive/emergency

contraception/Gynaecosid)

Other medications not effective for MR $\ddagger$

Advice given when client asks about MR services†

Offers MR medications

Advises them to continue with pregnancy

Refers to health facility/medical provider/counseling

Refers to traditional health provider

Stocked and sold misoprostol in past three mos. (for any indication including MR)

Sells misoprostol for other conditions (not MR-related)

RESPONDENTS WHO STOCKED AND SOLD MISOPROSTOL IN LAST THREE

MOS. $(\mathrm{N}=746)$

Questions asked before offering MR medications†

Date of LMP

Allergy to medications/medical history

Whether end-user tried any MR/emergency contraception since LMP

Whether IUD inserted

Any personal details (permission from third party, background, reason for wanting MR)

\section{Conditions when would not provide MR medicationst}

No reasons

Pregnancy too advanced ( $>9$ weeks since LMP)

Pregnancy too advanced ( $>7$ weeks since LMP)

Lactating mother

Medical history/allergy/possible drug reaction/fever or infection

IUD inserted

\section{Post-MR care}

Gives phone number to call for more information§

Refers to health facility in cases of heavy bleeding/incomplete MR/infection

Offers family planning services after misoprostol for MR§

53.5

87.8

\section{Selling practices and reported purchasing}

Sells misoprostol for MR without prescription

Mean price of lowest- and highest-cost brands for $200 \mu \mathrm{g}$ of misoprostol†t, $\neq \neq$

RESPONDENTS WHO SELL COMBINATION REGIMEN $(\mathrm{N}=290)$

\section{Selling practices and reported purchasing}

Mean price of combination brand $1+\dagger$

Mean price of combination brand $2+\dagger$

Median estimated no. of MR clients who purchase the combination regimen permo.§

tMultiple responses were allowed. ‡Includes herbal medicine, iron pills, worm tablets, folic acid and paracetamol. §Missing one value. †+Price calculated using mean exchange rate for 2013 of 78.1 Bangladesh taka to US\$1. \#¥Missing 20 values. §§Missing 33 values. Notes: MR=menstrual regulation. LMP=last menstrual period. Figures in parentheses are standard deviations or interquartile ranges.

\section{DISCUSSION}

This national cross-sectional study of Bangladeshi drug sellers' knowledge and provision provides a vital snapshot of on-the-ground provision practices of different drugs for MR in 2013-2014, just as the mifepristone-misoprostol regimen started to become available legally. The main findings highlight that despite misoprostol-only being sold for MR almost universally (and in most cases, without a prescription), drug sellers were generally confused about the most effective regimen to induce MR, the appropriate 
TABLE 3. Proportion of drug sellers who stocked and sold misoprostol in the last three months, by measures of training on misoprostol for menstrual regulation and knowledge of effective regimen, eligibility, side effects and complications

Measure $\%$ $(\mathrm{N}=746)$

\section{TRAINING}

On misoprostol for MR

Received training, detailing or information from any organization (including $\quad 71.5$ call center)

Received nongovernmental organization-led training

Received pharmaceutical company detailing

Used call centert

Received other training

Feel they have enough informationt

\section{Would like more information about}

Misoprostol regimen

Knowing when to prescribe MR medications

Side effects/complications

Legal issues

KNOWLEDGE OF MISOPROSTOL-ONLY MR REGIMEN

Knows correct regimen $\ddagger$,

No

Yes
Yo

Dosage per dose

$<800 \mu \mathrm{g}$

$800 \mu \mathrm{g}$ (correct answer)

$>800 \mu \mathrm{g}$

Don't know

No. of doses

$<3$

3 (correct answer)

$>3$

Don't know

\section{Hours between doses}

$<3$

3 (correct answer)

$>3$

Don't know

\section{Route of administration}

Vaginal, buccal, or sublingual (correct answer)

Oral (swallowed) or rectal

Total misoprostol dose (dosage per dose $\mathrm{x}$ number of doses) $+\dagger$

$<2,400 \mu \mathrm{g}$

$2,400 \mu \mathrm{g}$ (correct answer)

$>2,400 \mu \mathrm{g}$

Don't know

Eligibility (maximum time since last menstrual period that medication MR

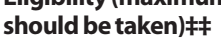

1-8 weeks

9 weeks (correct answer)

10-12 weeks

$>12$ weeks

Identified five potential side effects of misoprostol correctly§§

†Missing one value. ‡Defined as knowing the correct dosage per dose (800), number of doses (3), hours between doses (3) and at least one route of administration (buccal, sublingual or vaginal). $\S$ Missing 10 values. ††Missing 20 values. ‡¥Missing 27 values. §§From the following list: pain, nausea/vomiting, headache, vertigo, bleeding, fever/chills and weakness. †łInfection/fever and prolonged or heavy bleeding.

period of time to use MR after the last menstrual period and contraindications. This is largely consistent with results from a systematic review of pharmacy medication abortion provision, which found that sales of MR medicines without a prescription in low-income settings were common. ${ }^{19}$ For five years prior to the survey, interventions had been conducted in Bangladesh to educate formal- and informal-sector drug sellers about the correct off-label use of misoprostol for MR. Despite NGO-led training, pharmaceutical company detailing and call center support for off-label use of misoprostol for uterine evacuation, drug sellers typically did not know how to use misoprostol correctly. Although knowledge of the correct, most effective regimen for using misoprostol-only for MR was higher than the 7\% reported in a 2011 mystery client study, it was still low (19\%). The heterogeneous picture of drug sellers' knowledge and provision of misoprostol presented here is relevant for understanding medication abortion practices in other low-income settings where legal medication abortion is not currently available and off-label use of misoprostol-only is the most widely used treatment, such as in many countries in Latin America and Sub-Saharan Africa. ${ }^{19}$

A worrying finding was that many drug sellers did not know the length of time after the last menstrual period that misoprostol should be used (nine weeks is recommended in this context, and second-trimester use requires a reduced dose), ${ }^{8}$ and many lacked knowledge of the side effects and possible complications associated with misoprostol. Fewer than half reported asking such key screening questions for MR as date of the last menstrual period, medical history, use of MR or emergency contraception since the last menstrual period and whether the end user had an IUD inserted. A further concern was that a third of drug sellers identified a dose lower than that recommended by WHO at the time of the study, ${ }^{8}$ which could lead to higher rates of incomplete $\mathrm{MR}^{20,21}$ and potentially greater abortion-related morbidity, as women may be past the time limit for clinic-based MR and may then turn to less-safe methods to complete their MR. Similarly, low knowledge of the upper gestational limit could lead to administration of MR medications at later gestational ages, which is also associated with higher rates of incomplete procedures. $^{24}$

The misoprostol-only regimen for MR was sold by more than three times as many drug sellers as the officially approved combination regimen, which is perhaps unsurprising since the first combination pack brand was registered just nine months before data collection started. Slightly more than half of drug sellers had heard of at least one brand of the combination regimen, suggesting that drug seller awareness may be an important barrier to the uptake of mifepristone-misoprostol. Affordability could also affect use; while the cost of the combination regimen was not much higher than the most effective misoprostolonly regimen, one-third of drug sellers reported that they sell the misoprostol-only MR treatment at a suboptimal dose (fewer than 12 tablets), which lowers its cost. In 2014-2015, a study conducted in three districts of Bangladesh also found that both regimens were still being used, but awareness and use of the combination pack had increased. The study had two parts-first, in a face-to-face 


\begin{tabular}{|c|c|c|c|c|}
\hline \multirow[t]{2}{*}{ Characteristic } & \multirow{2}{*}{$\begin{array}{l}\text { Did not have } \\
\text { correct knowledge } \\
\% \\
(\mathrm{~N}=550)\end{array}$} & \multirow{2}{*}{$\begin{array}{l}\text { Had correct } \\
\text { knowledge } \\
\% \\
(\mathrm{~N}=128)\end{array}$} & \multicolumn{2}{|l|}{ Odds ratios } \\
\hline & & & Crude & Adjusted \\
\hline \multicolumn{5}{|c|}{ Received nongovernmental organization-led training } \\
\hline Yes & 67.2 & 32.8 & $2.31(1.32-4.06)^{* *}$ & $1.96(1.03-3.72)^{*}$ \\
\hline \multicolumn{5}{|l|}{ Received pharmaceutical company detailing } \\
\hline No (ref) & 83.7 & 16.3 & 1.00 & 1.00 \\
\hline Yes & 79.6 & 20.4 & $1.31(0.87-1.97)$ & $1.27(0.80-2.00)$ \\
\hline \multicolumn{5}{|l|}{ Used call center } \\
\hline No (ref) & 83.6 & 16.4 & 1.00 & 1.00 \\
\hline Yes & 74.3 & 25.7 & $1.77(1.17-2.66)^{* *}$ & $1.86(1.15-2.99)^{*}$ \\
\hline \multicolumn{5}{|l|}{ Received other training } \\
\hline No (ref) & 80.2 & 19.8 & 1.00 & 1.00 \\
\hline Yes & 90.5 & 9.5 & $0.43(0.18-1.01)$ & $0.48(0.18-1.20)$ \\
\hline \multicolumn{5}{|l|}{ No.of workers } \\
\hline 1 (ref) & 79.7 & 20.3 & 1.00 & 1.00 \\
\hline 2 & 81.7 & 18.4 & $0.88(0.57-1.38)$ & $0.87(0.53-1.43)$ \\
\hline$\geq 3$ & 82.8 & 17.2 & $0.81(0.50-1.33)$ & $0.97(0.54-1.75)$ \\
\hline \multicolumn{5}{|l|}{ Division } \\
\hline Dhaka (ref) & 70.4 & 29.6 & 1.00 & 1.00 \\
\hline Khulna & 83.2 & 16.8 & $0.48(0.24-0.95)^{*}$ & $0.43(0.21-0.90)^{*}$ \\
\hline Chittagong & 91.5 & 8.5 & $0.22(0.91-0.54)^{* *}$ & $0.19(0.07-0.49)^{* * *}$ \\
\hline Rangpur & 92.5 & 7.5 & $0.19(0.08-0.47)^{* * *}$ & $0.22(0.09-0.58)^{* *}$ \\
\hline Rajshahi & 71.8 & 28.2 & $0.93(0.51-1.72)$ & $0.86(0.44-1.69)$ \\
\hline Sylhet & 76.8 & 23.2 & $0.72(0.38-1.37)$ & $0.76(0.38-1.52)$ \\
\hline Barisal & 83.9 & 16.0 & $0.45(0.23-0.89)^{*}$ & $0.45(0.22-0.93)^{*}$ \\
\hline \multicolumn{5}{|c|}{ No. of customers sold misoprostol for MR per mo. } \\
\hline$<5$ (ref) & 80.3 & 19.7 & 1.00 & 1.00 \\
\hline$\geq 5$ & 81.8 & 18.3 & $0.91(0.62-1.34)$ & $0.72(0.47-1.13)$ \\
\hline \multicolumn{5}{|l|}{ Age } \\
\hline$<30$ (ref) & 79.2 & 20.8 & 1.00 & 1.00 \\
\hline $30-39$ & 81.9 & 18.1 & $0.84(0.52-1.36)$ & $0.89(0.51-1.56)$ \\
\hline$\geq 40$ & 81.6 & 18.5 & $0.86(0.52-1.42)$ & $1.08(0.59-1.99)$ \\
\hline \multicolumn{5}{|l|}{ Education } \\
\hline$\leq$ secondary (ref) & 81.0 & 19.0 & 1.00 & 1.00 \\
\hline Higher secondary certificate & 78.7 & 21.3 & $1.16(0.75-1.79)$ & $1.17(0.73-1.88)$ \\
\hline$\geq$ bachelor's & 84.7 & 15.3 & $0.77(0.46-1.29)$ & $0.89(0.51-1.58)$ \\
\hline \multicolumn{5}{|l|}{ Professional pharmacy training } \\
\hline None (ref) & 75.7 & 24.3 & 1.00 & 1.00 \\
\hline$<1$ year & 82.5 & 17.5 & $0.66(0.37-1.19)$ & $0.66(0.33-1.31)$ \\
\hline 1-2-year government-approved diploma & 72.9 & 27.1 & $1.16(0.50-2.68)$ & $1.25(0.48-3.26)$ \\
\hline \multicolumn{5}{|l|}{ No. of years in profession } \\
\hline$<10$ (ref) & 78.5 & 21.5 & 1.00 & 1.00 \\
\hline$\geq 10$ & 82.6 & 17.4 & $0.77(0.52-1.14)$ & $0.67(0.41-1.10)$ \\
\hline \multicolumn{5}{|l|}{ No. of years selling misoprostol for MR } \\
\hline$<2$ (ref) & 84.4 & 15.6 & 1.00 & 1.00 \\
\hline$\geq 2$ & 79.6 & 20.4 & $1.39(0.90-2.14)$ & $1.65(1.01-2.70)^{*}$ \\
\hline \multicolumn{5}{|l|}{ Owner of drug shop } \\
\hline No (ref) & 81.5 & 18.5 & 1.00 & 1.00 \\
\hline Yes & 78.2 & 21.8 & $1.23(0.69-2.18)$ & $1.14(0.54-2.39)$ \\
\hline \multicolumn{5}{|l|}{ Sells misoprostol for other conditions } \\
\hline No (ref) & 75.8 & 24.2 & 1.00 & 1.00 \\
\hline Yes & 85.2 & 14.8 & $0.54(0.37-0.80)^{* *}$ & $0.69(0.45-1.07)$ \\
\hline
\end{tabular}


survey, $86 \%$ and $78 \%$ of pharmacy workers mentioned misoprostol and the combination pack, respectively, as a medication for MR. ${ }^{6}$ In the second part, mystery clients visited pharmacies to ask for medications to regulate their or someone else's menstruation; $51 \%$ were sold misoprostol alone and $69 \%$ the combination pack. ${ }^{6}$ The survey found that $54 \%$ of those sold the combination pack were given the recommended dosage; information on misoprostol dosage or training was not available.

It is encouraging that use of a call center and NGO-led training were associated with greater knowledge of the correct misoprostol-only regimen among drug sellers. This study joins a growing body of evidence indicating that interventions with pharmacy workers, either through pharmaceutical company detailing or dedicated training sessions, ${ }^{19}$ can improve accessibility, knowledge and attitudes toward medication abortion and may be of use in contexts in which the combination pack is not available. Successful interventions among pharmacists have also been shown to improve care quality and coverage of emergency contraception provision. ${ }^{25}$ In Bangladesh, drug sellers would ideally refer clients to legal providers who offer a comprehensive package of care, including post-MR family planning counseling and services. However, barriers to clinic services are likely to remain, and effective training of drug sellers could operate as a harm reduction strategy to ensure that where medication MR is happening without a prescription, it is done so safely. Key information to be conveyed to drug sellers includes awareness of the combination pack, the gestational limit for using medications for MR, possible complications and referral options. The correct misoprostol-only regimen for MR should also be disseminated if this option continues to be widely used, which is possibly because of its lower cost; however, priority should now be given to increasing access to the combination pack, given its higher effectiveness and lower likelihood of incorrect use.

A number of issues should be considered when planning interventions to support drug seller provision of MR medications in this setting where outlets are prolific and unregulated. Pharmaceutical company detailing achieved much greater coverage than the call center and training ( $62 \%$ vs. $27 \%$ and $9 \%$ ); however, it was not associated with correct knowledge. Cost information was not available for all of the interventions; it is likely that the costs of scaling up intensive training across the estimated 210,000 registered and unregistered drug shops operating in Bangladesh ${ }^{17}$ would be prohibitive. The lack of evidence of an effect of pharmaceutical company detailing here could reflect that there may be little incentive for pharmaceutical detailers to spend time educating drug sellers on a product with relatively low sales, but the approach may be worth exploring further, particularly given the evidence that this approach has been successful in improving STI services in Bangladesh. ${ }^{26}$ Reviews of pharmacist training interventions have concluded that education is most effective when part of a multifaceted approach that includes referral networks, printed materials, special branding and social marketing. ${ }^{27-30}$ Mobile phone interventions that include SMS services, apps or websites could also be considered; in other contexts, smartphones have been used effectively to improve health care worker education, and to help them support follow up and adherence to medications and to collect information. ${ }^{31}$

The drug sellers interviewed were aware of their knowledge gaps. Nearly all reported that they needed more information on MR medications (particularly on the misoprostol-only regimen), when to prescribe medications, on side effects and on complications, which indicates that they may be motivated to use these types of "pull" strategies. It may be unrealistic, however, to expect drug sellers to provide comprehensive counseling to MR clients, given that they have little financial incentive to do so, many have no professional training, and a lengthy conversation on this topic may be inappropriate or unacceptable to the user in such a public setting. Future approaches could also be targeted to increase the information available to the end user and to other community health providers; SMS has been used in South Africa to support abortion clients to assess abortion completion, ${ }^{32}$ and in Cambodia, recorded voice message reminders linked to call-center counseling have increased postabortion contraceptive use. ${ }^{33}$

\section{Limitations}

The study had some limitations that need to be considered when interpreting the findings. Given the relatively restricted nature of MR medication provision, the survey responses are likely to be subject to reporting bias. Data such as the volume of clients, prices of medications, referral advice, and the information and drug regimen shared with clients may not reflect actual practices; this was observed in a recent study among Indian pharmacists where abortion practices reported in face-to-face interviews with pharmacy workers were different from those experienced during mystery client visits. ${ }^{34}$ Responses may also be subject to recall bias: The interventions had been running for a number of years prior to the interview, so the details of interventions accessed may not be accurate. The sample may also not be representative of all drug shops operating in Bangladesh: Through necessity, we used a sampling frame consisting of shops supplied with misoprostol by one pharmaceutical company, which may have overestimated the availability of the product and the type of pharmacy being surveyed, and underrepresented more informal drug shops, which purchase products through secondary suppliers. As the pharmaceutical company used for sampling delivered detailing on misoprostol use and complications, the respondents may have been more knowledgeable than a completely random sample of drug shops. Selection of drug shops for NGO-led training and pharmaceutical company detailing could have been influenced by factors, such as an existing high MR demand or perceived capability to provide an effective service. Lastly, the cross-sectional design limits any causal interpretation 
of the association between intervention exposure and enhanced knowledge. Unmeasured confounding may be an issue: Respondents who used the call center could have background traits such as greater conscientiousness, which suggests that their knowledge may have been higher regardless of call center use.

\section{Conclusions}

This study validates other research in Bangladesh that has found that drug shop provision of medications for MR is widespread but knowledge of correct provision practices among drug sellers is poor, and to our knowledge, is the first to examine interventions aimed at improving practice. To further reduce harm from unsafe abortion in Bangladesh, future efforts should aim to enhance access to safe, legal methods of MR, expand training of drug sellers through a range of strategies and explore ways to target the end-user directly. A more robust quasi or fully experimental evaluation of initiatives that may improve quality of MR services provided to women in the community is needed. Mystery client visits and interviews with end-users of the medications could be employed alongside or instead of face-to-face interviews to ensure impacts measured are not limited to knowledge but capture provision practices and outcomes of the procedure.

\section{REFERENCES}

1. Government of the People's Republic of Bangladesh, Ministry of Health and Family Welfare and Directorate General of Family Planning (DGFP), Bangladesh National Menstrual Regulation Service Guidelines, Dhaka, Bangladesh: DGFP, 2014

2. Dixon-Mueller R, Innovations in reproductive health care: menstrual regulation policies and programs in Bangladesh, Studies in Family Planning, 1988, 19(3):129-140, doi:10.2307/1966749.

3. Singh $\mathrm{S}$ et al., The incidence of menstrual regulation procedures and abortion in Bangladesh, 2014, International Perspectives on Sexual and Reproductive Health, 2017, 43(1):1-11, doi:10.1363/43e2417.

4. Government of the People's Republic of Bangladesh, Ministry of Health and Family Welfare and DGFP, Bangladesh National Service Delivery Guideline on Menstrual Regulation with Medication (MRM), Dhaka, Bangladesh: DGFP, 2015, https://abortion-policies.srhr.org/ documents/countries/06-BANGLADESH-NATIONAL-SERVICEDELIVERY-GUIDELINE-ON-MENSTRUAL-REGULATION-WITHMEDICATION.pdf.

5. Huda FA et al., Availability and provision of misoprostol and other medicines for menstrual regulation among pharmacies in Bangladesh via mystery client survey, International Journal of Gynecology \& Obstetrics, 2014, 124(2):164-168, doi:10.1016/j. ijgo.2013.07.037.

6. Huda FA et al., Provision of menstrual regulation with medication among pharmacies in three municipal districts of Bangladesh: a situation analysis, Contraception, 2018, 97(2):144-151, doi:10.1016/j. contraception.2017.11.006.

7. Winikoff B and Sheldon W, Use of medicines changing the face of abortion, International Perspectives on Sexual and Reproductive Health, 2012, 38(3):164-166, doi:10.1363/3816412.

8. World Health Organization (WHO), Medical Management of Abortion, Geneva: WHO, 2018, https://www.who.int/ reproductivehealth/publications/medical-management-abortion/en/.

9. Hyman A et al., Misoprostol in women's hands: a harm reduction strategy for unsafe abortion, Contraception, 2013, 87(2):128-130, doi:10.1016/j.contraception.2012.10.020.
10. Miller S et al., Misoprostol and declining abortionrelated morbidity in Santo Domingo, Dominican Republic: a temporal association, BJOG, 2005, 112(9):1291-1296, doi:10.1111/j.1471-0528.2005.00704.x.

11. Sherris J et al., Misoprostol use in developing countries: results from a multicountry study, International Journal of Gynecology $\&$ Obstetrics, 2005, 88(1):76-81, doi:10.1016/j.ijgo.2004.09.006.

12. Billings DL et al., Pharmacy worker practices related to use of misoprostol for abortion in one Mexican state, Contraception, 2009, 79(6):445-451, doi:10.1016/j.contraception.2008.12.011.

13. Goel P et al., Retail pharmacies in developing countries: a behavior and intervention framework, Social Science $\mathcal{E}$ Medicine, 1996, 42(8):1155-1161, doi:10.1016/0277-9536(95)00388-6.

14. Rahman MH and Agarwal S, Drug detailers and the pharmaceutical market in Bangladesh, in: Bloom G et al., eds., Transforming Health Markets in Asia and Africa: Improving Quality and Access for the Poor, London: Routledge, 2012, pp. 58-70.

15. National Institute of Population Research and Training (NIPORT), Mitra and Associates, and ICF International, Bangladesh Demographic and Health Survey 2014, Dhaka, Bangladesh and Rockville, MD, USA: NIPORT, Mitra and Associates, and ICF International, 2016.

16. Rashid SF, Akram O and Standing H, The sexual and reproductive health care market in Bangladesh: Where do poor women go? Reproductive Health Matters, 2011, 19(37):21-31, doi:10.1016/S0968-8080(11)37551-9.

17. Uzzal M, 50\% pharmacies unregistered, Dhaka Tribune, July 4, 2014, http://www.dhakatribune.com/ uncategorized/2014/07/04/50-pharmacies-unregistered.

18. Government of the People's Republic of Bangladesh, Ministry of Health and Family Welfare and Directorate General of Drug Administration (DGDA), Standards for the Establishment and Operations of Model Pharmacies and Model Medicine Shops, Dhaka, Bangladesh: DGDA, 2016.

19. Footman K et al., Medical abortion provision by pharmacies and drug sellers in low- and middle-income countries: a systematic review, Studies in Family Planning, 2018, 49(1):57-70, doi:10.1111/ sifp. 12049.

20. Blanchard K et al. Misoprostol alone for early abortion: an evaluation of seven potential regimens, Contraception, 2005, 72(2):91-97, doi:10.1016/j.contraception.2005.02.008.

21. Carbonell I Esteve JL et al., Misoprostol 3, 4 or 5 days after methotrexate for early abortion: a randomized trial, Contraception, 1997, 56(3):169-174, doi:10.1016/S0010-7824(97)00121-2

22. Eckersberger E, Ipas, Chapel Hill, NC, USA, personal communication, Mar. 15, 2015

23. Footman K et al., Feasibility of assessing the safety and effectiveness of menstrual regulation medications purchased from pharmacies in Bangladesh: a prospective cohort study, Contraception, 2018, 97(2):152-159, doi:10.1016/j.contraception.2017.08.002.

24. Kahn JG et al., The efficacy of medical abortion: a metaanalysis, Contraception, 2000, 61(1):29-40, doi:10.1016/ S0010-7824(99)00115-8

25. Liambila W, Obare F and Keesbury J, Can private pharmacy providers offer comprehensive reproductive health services to users of emergency contraceptives? Evidence from Nairobi, Kenya, Patient Education and Counseling, 2010, 81(3):368-373, doi:10.1016/ j.pec. 2010.09.001.

26. Sarma H and Oliveras E, Improving STI counselling services of nonformal providers in Bangladesh: testing an alternative strategy, Sexually Transmitted Infections, 2011, 87(6):476-478, doi:10.1136/ sextrans-2011-050014.

27. Shah NM, Brieger WR and Peters DH, Can interventions improve health services from informal private providers in low- and middleincome countries?: A comprehensive review of the literature, Health Policy and Planning, 2011, 26(4):275-287, doi:10.1093/heapol/ czq074. 
28. Smith F, Private local pharmacies in low- and middle-income countries: a review of interventions to enhance their role in public health, Tropical Medicine E International Health, 2009, 14(3):362372, doi:10.1111/j.1365-3156.2009.02232.x

29. Wafula FN and Goodman CA, Are interventions for improving the quality of services provided by specialized drug shops effective in Sub-Saharan Africa? A systematic review of the literature, International Journal for Quality in Health Care, 2010, 22(4):316-323, doi:10.1093/intqhe/mzq022.

30. Sneeringer RK et al., Roles of pharmacists in expanding access to safe and effective medical abortion in developing countries: a review of the literature, Journal of Public Health Policy, 2012, 33(2):218-229, doi:10.1057/jphp.2012.11.

31. Ozdalga E, Ozdalga A and Ahuja N, The smartphone in medicine: a review of current and potential use among physicians and students, Journal of Medical Internet Research, 2012, 14(5):e128, doi:10.2196/jmir.1994

32. Constant D et al., Assessment of completion of early medical abortion using a text questionnaire on mobile phones compared to a self-administered paper questionnaire among women attending four clinics, Cape Town, South Africa, Reproductive Health Matters, 2015, 22(44, Suppl. 1):83-93, doi:10.1016/S0968-8080 (14)43791-1.

33. Smith $C$ et al., Effect of a mobile phone-based intervention on post-abortion contraception: a randomized controlled trial in Cambodia, Bulletin of the World Health Organization, 2015 93(12):842-850A, doi:10.2471/BLT.15.160267.

34. Powell-Jackson T et al., Delivering medical abortion at scale: a study of the retail market for medical abortion in Madhya Pradesh India, PLOS ONE, 2015, 10(3):e0120637, doi:10.1371/journal. pone.0120637.

\section{RESUMEN}

Contexto: En Bangladesh, antes de que el régimen combinado de mifepristona y misoprostol fuera aprobado para la regulación menstrual (RM), la provisión sin receta de regímenes de misoprostol solo para RM por parte de vendedores de medicamentos estuvo muy generalizada, pero la calidad de servicio era deficiente. Examinar las prácticas de los proveedores relacionadas con la provisión de misoprostol solo en Bangladesh podría aumentar la comprensión sobre el uso y la provisión de misoprostol en otros entornos de bajos recursos restringidos legalmente.

Métodos: Entre 2013 y 2014, se realizó una encuesta transversal de conocimientos, actitudes y prácticas en todo el país entre 777 vendedores de medicamentos seleccionados al azar; los datos fueron analizados descriptivamente. Se utilizó regresión logística para evaluar las asociaciones entre la exposición a tres intervenciones diseñadas para mejorar las prácticas de los vendedores de medicamentos (capacitación conducida por una organización no gubernamental [ONG], un centro de atención telefónica y capacitación en el negocio por parte de representantes de las compañias farmacéuticas), así como el conocimiento correcto del régimen de misoprostol solo usado para RM.

Resultados: Casi la totalidad (97\%) de los vendedores de medicamentos informaron que estaban vendiendo medicamentos para RM; que la venta de misoprostol solo era más común que el régimen combinado (96\% vs 26\%). El nueve por ciento había recibido capacitación impartida por ONG, el
62\% había recibido capacitación en su negocio de un representante de una compañía farmacéutica y el 27\% había utilizado el centro de llamadas. En general, el 19\% de los vendedores de medicamentos conocía el régimen correcto de RM basado en misoprostol solo y el 74\% quería más información sobre ese régimen. El conocimiento correcto del régimen se asoció positivamente con la recepción de capacitación de las ONG y la utilización del centro de atención telefónica (razón de probabilidades, 2.0 y 1.9, respectivamente).

Conclusiones: La capacitación conducida por ONG y el uso del centro de atención telefónica deberían considerarse en otros entornos restringidos en los que el misoprostol solo se proporciona sin autorización para la interrupción del embarazo.

\section{RÉSUMÉ}

Contexte: Au Bangladesh, avant la disponibilité du traitement homologué au mifépristone associé au misoprostol pour la régulation menstruelle (RM), la prestation par les vendeurs de médicaments des traitements de RM au misoprostol seul sans ordonnance était répandue, mais la qualité du service était faible. L'examen des pratiques de prestation relatives à la fourniture de misoprostol seul au Bangladesh peut aider à mieux cerner l'usage et l'offre de ce médicament dans d'autres contextes à faibles ressources soumis à des lois restrictives.

Méthodes: En 2013-2014, une étude transversale sur les connaissances, les attitudes et les pratiques à l'échelle du pays a été menée auprès de 777 vendeurs de médicaments sélectionnés aléatoirement, pour analyse descriptive des données. La régression logistique a servi au test des associations entre l'exposition à trois interventions conçues pour améliorer la pratique des vendeurs de médicaments (formation sous la conduite d'organisations non gouvernementales [ONG], établissement d'un centre d'appels et formation par des représentants de laboratoires pharmaceutiques) et la connaissance correcte du traitement de RM à base de misoprostol seul.

Résultats: Presque tous les vendeurs de médicaments (97\%) ont déclaré vendre des médicaments destinés à la RM. Le misoprostol seul était vendu plus fréquemment que le traitement d'association (96\% vs 26\%). Neuf pour cent avaient bénéficié d'une formation par une ONG, 62\% d'une formation locale assurée par un représentant de laboratoire pharmaceutique et $27 \%$ avaient eu recours au centre d'appels. Globalement, $19 \%$ des vendeurs avaient une connaissance correcte du traitement de RM à base de misoprostol seul et 74\% désiraient plus d'information à ce sujet. La connaissance correcte du traitement était associée positivement à l'obtention d'une formation par une ONG et au recours au centre d'appels (RC, 2,0 et 1,9, respectivement).

Conclusions: La formation sous la conduite d'une ONG et l'établissement d'un centre d'appels doivent être envisagés dans d'autres contextes sujets à une législation restrictive dans lesquels le misoprostol seul est proposé hors indication pour l'interruption d'une grossesse.

Author contact: kate.reiss@lshtm.ac.uk 